\title{
Effect of Disease Severity in Asthma and Chronic Obstructive Pulmonary Disease on Inhaler-Specific Inhalation Profiles Through the ELLIPTA ${ }^{\circledR}$ Dry Powder Inhaler
}

\author{
David Prime, PhD, Wilfried de Backer, MD, ${ }^{2}$ Melanie Hamilton, BSc, ${ }^{1}$ Anthony Cahn, MB, BS, PhD, ${ }^{3}$ \\ Andrew Preece, BSc, ${ }^{4}$ Dennis Kelleher, $\mathrm{PhD},{ }^{5}$ Amanda Baines, BSc, ${ }^{3}$ Alison Moore, $\mathrm{PhD},{ }^{4}$ \\ Noushin Brealey, MRCGP, MSc, ${ }^{4}$ and Jackie Moynihan, $\mathrm{MSc}^{6}$
}

\begin{abstract}
Background: Two studies were undertaken to characterize the maximal effort inhalation profiles of healthy subjects and patients with asthma or chronic obstructive pulmonary disease (COPD) through a moderateresistance dry powder inhaler (DPI). Correlations between inhaler-specific inhalation characteristics and inhaler-independent lung function parameters were investigated.

Methods: Healthy subjects $(n=15)$, patients with mild, moderate, or severe asthma $(n=45)$, and patients with mild, moderate, severe, or very-severe COPD $(n=60)$ were included in the studies. Inhalation pressure drop versus time profiles were recorded using an instrumented ELLIPTA ${ }^{\circledR}$ DPI or bespoke resistor component with equivalent resistivity. Inhaler-independent lung function assessments included pharyngometry, spirometry, plethysmography, and diffusion.

Results: For the inhaler-specific inhalation profiles, the mean maximal effort peak inspiratory flow rates (PIFRs) varied across the subgroups from 65.8-110.6 L/min (range: 41.6-142.9). Peak pressure drop, PIFR, inhaled volume, and average inhalation flow rate (primary endpoints) did not differ markedly between healthy subjects and patients with asthma or mild COPD. Moderate, severe, and very-severe COPD patients demonstrated lower mean peak pressure drops, PIFRs and inhaled volumes, which tended to decrease with increasing COPD severity. Severe and very-severe COPD patients demonstrated shorter mean inhalation times compared with all other participants. Inhaler-independent lung function parameters were consistent with disease severity, and statistically significant $(p<0.05)$ strong correlations $(\mathrm{R}>0.7)$ with components of the inhaler-specific inhalation profiles were observed in the COPD cohort; correlations in the asthma cohort tended to be weaker.

Conclusions: All participants achieved a maximal effort PIFR $\geq 41.6 \mathrm{~L} / \mathrm{min}$ through the moderate resistance of the ELLIPTA inhaler. Patients with asthma achieved similar inhalation profiles to healthy subjects, but increasing COPD severity tended to reduce a patient's inhalation capability. Correlation analyses suggest that some lung function parameters may be a useful indicator of ability to inhale efficiently through a moderateresistance DPI, such as the ELLIPTA inhaler.
\end{abstract}

Key words: asthma, COPD, dry powder inhalers, inhalation profile, lung function

${ }^{1}$ GSK Research and Development Ltd., Ware, Hertfordshire, United Kingdom.

${ }^{2}$ Department of Pulmonary Medicine, University Hospital and University of Antwerp, Belgium.

${ }^{3}$ Medicines Discovery and Development, GSK, Stevenage, Hertfordshire, United Kingdom.

${ }_{5}^{4}$ Respiratory Therapy Area Unit, GSK, Stockley Park West, Middlesex, United Kingdom.

${ }^{5}$ GSK, Research Triangle Park, Durham, North Carolina, USA.

${ }^{6}$ Synergy Clinical, Langley, Berks, United Kingdom.

(c) The Author(s) 2015; Published by Mary Ann Liebert, Inc. This Open Access article is distributed under the terms of the Creative Commons Attribution Noncommercial License (http://creativecommons.org/licenses/by-nc/4.0/) which permits any noncommercial use, distribution, and reproduction in any medium, provided the original author(s) and the source are credited. 


\section{Introduction}

D RY POWDER INHALERS (DPIs) are increasingly used to deliver medication to the airways for the treatment of asthma and chronic obstructive pulmonary disease (COPD), as they are easy to use with no requirement for patients to coordinate actuation with inhalation. ${ }^{(1)}$ Treatment outcomes for any inhaled therapy depend on the compatibility of patient characteristics (e.g., dexterity, inhalation capability) with inhaler product characteristics (e.g., ease-of-use, dosing performance). ${ }^{(2-4)}$ Inhalation capability can be affected by factors such as the presence and severity of disease, while dosing performance depends on characteristics of a patient's inhalation profile, specifically flow rate, inhaled volume, and perhaps flow acceleration rate. ${ }^{(2-4)}$ Therefore, patients are required to achieve a minimum level of inspiratory effort through a DPI to generate sufficient flow to deliver the powder from the inhaler; ${ }^{(5)}$ the flow that can be achieved depends on the internal resistance of the inhaler. ${ }^{(6,7)}$

The ELLIPTA ${ }^{\circledR}$ DPI (GSK, Middlesex, UK; ELLIPTA ${ }^{\circledR}$ is a trademark of the GSK group of companies) has been developed for the delivery of a portfolio of once-daily therapies for the treatment of asthma and COPD (Grant et al., J Aerosol Med Pulm Drug Deliv, in press). In summary, it can contain either a single or two multi-dose foil laminate blister strips pre-filled with a blend of drug and excipient. The blister strips hold up to 30 doses, equivalent to one month's supply of once-daily treatment. The strips are not accessible to the patient and help to protect the contents from environmental moisture and contaminants.

The separate strips enable the inhaler to be used for the delivery of up to two separate formulations, allowing for the delivery of mono- or combination therapies, including combinations that need to be developed separately to improve performance and/or stability. Upon inhalation, air enters the inhaler through grills in the top cover. A portion of the inlet air is then guided, by cruciform airflow ports, through the blister pocket (or pockets) to aerosolize the dose, which is inhaled through the mouthpiece and into the patient's airways.

The ELLIPTA inhaler is used to deliver a range of medications for the treatment of asthma and/or COPD, including umeclidinium (UMEC) monotherapy and UMEC/vilanterol (VI) combination therapy for COPD, fluticasone furoate (FF) monotherapy for asthma, and FF/VI combination therapy for asthma and COPD. The inhaler has been reported to be easy and intuitive to use, was associated with high patient satisfaction, and was preferred to other inhalers. ${ }^{8-10)}$

It was designed with a moderate resistance to patient inspiratory effort (typical specific resistance for the singlestrip configuration: $0.0258 \mathrm{kPa}^{0.5}[\mathrm{~L} / \mathrm{min}]^{-1}$; two-strip configuration: $0.0286 \mathrm{kPa}^{0.5}[\mathrm{~L} / \mathrm{min}]^{-1}$ ) so that it can be comfortably used by patients with a wide range of disease severities; the resistance is similar to that of the DISKUS ${ }^{\circledR}$ DPI (also known as ACCUHALER ${ }^{\circledR}$; GSK, North Carolina, USA; DISKUS $^{\circledR}$ and ACCUHALER ${ }^{\circledR}$ are trademarks of the GSK group of companies). ${ }^{(11)}$

This article reports findings from two studies in which the aim was to characterize the maximal effort inhalation profiles of healthy subjects and patients with asthma and COPD (with a range of disease severities) through a moderateresistance DPI. To support development of the ELLIPTA inhaler, either an instrumented ELLIPTA inhaler or bespoke resistor component with equivalent resistivity was used in these studies. The data collected were then used to examine the correlation between inhaler-specific inhalation profiles and inhaler-independent lung function parameters.

In a separate publication (Hamilton et al., J Aerosol Med Pulm Drug Deliv, in press), we also describe how these profiles were replicated in vitro using the electronic lung (eLung ${ }^{\mathrm{TM}}$; GSK, Ware, UK; eLung ${ }^{\mathrm{TM}}$ is a trademark of the GSK group of companies) breathing simulator, to assess the dose delivery characteristics of the inhaler under patientrelevant conditions. This approach provides a more realistic estimation of in vivo product performance than standard in vitro testing. ${ }^{(12,13)}$

\section{Materials and Methods}

Study 1 (GSK study number RES113817, clinicaltrials .gov identifier NCT01345266) was conducted between February 1, 2010 and June 20, 2010, and Study 2 (RES117178, NCT02076269) was conducted between September 10, 2013 and February 19, 2014. In each study, assessments were performed at the same site in Antwerp, Belgium. There was one study clinic visit (Visit 1) that was preceded by a screening visit (within the previous 28 days); in Study 1, Screening and Visit 1 could be performed on the same day, in which case, assessments were not duplicated. Follow-up was within 2-5 days, and the maximum study duration was 33 days.

Both studies were conducted in accordance with International Conference on Harmonisation Good Clinical Practice guidance ${ }^{(14)}$ and the Declaration of Helsinki. ${ }^{(15)}$ Local ethics committee approvals were obtained and all participants gave informed consent prior to study participation.

\section{Study population}

In Study 1, healthy subjects and patients with asthma or COPD that had been clinically diagnosed for $\geq 6$ months, aged between 21 and 75 years, with a body weight $\leq 120 \mathrm{~kg}$ and body-mass index (BMI) of $18-35 \mathrm{~kg} / \mathrm{m}^{2}$ (inclusive) were eligible. Asthma patients were stratified according to disease severity, defined by the 2008 British Thoracic Society (BTS) guidance, ${ }^{(16)}$ as 'mild' (BTS steps 1 or 2), 'moderate' (BTS step 3), or 'severe' (BTS steps 4 or 5). COPD patients were stratified by disease severity according to the 2007 Global Initiative for Chronic Obstructive Lung Disease (GOLD) guidelines, ${ }^{(17)}$ as 'mild' (GOLD stage I), 'moderate' (GOLD stage II), 'severe' (GOLD stage III), or 'very-severe' (GOLD stage IV). Healthy subjects and asthma patients must have been non-smokers (never smoked or not smoked $\geq 12$ months, with $<1$ pack-year smoking history), while COPD patients were either ex-smokers or smokers with a history of $>10$ pack-years.

In Study 2, eligible patients were aged $\geq 40$ years with 'very-severe' COPD (GOLD stage IV, according to the 2013 update to the GOLD guidelines (which is now incorporated into the 2014 version), ${ }^{(18)}$ diagnosed with COPD $\geq 6$ months previously. Patients must have been ex-smokers or smokers with a history of $>10$ pack-years. Body weight and BMI were not restricted as this was not appropriate for the recruitment of very-severe COPD patients. 
The inclusion criteria for the 'very-severe' COPD subgroup differed slightly between the two studies. The postbronchodilator criteria in Study 1 was forced expiratory volume in one second $\left(\mathrm{FEV}_{1}\right)<30 \%$ or $\mathrm{FEV}_{1}<50 \%$ predicted plus chronic respiratory failure, whereas in Study 2 the post-bronchodilator $\mathrm{FEV}_{1}$ was required to be $<30 \%$ predicted. $\mathrm{FEV}_{1} /$ forced vital capacity $(\mathrm{FVC})$ was required to be $<70 \%$ in both studies.

Exclusion criteria for both studies are summarized in Supplementary e-Appendix 1 (supplementary material is available online at www.liebertpub.com/jamp).

\section{Study objectives and assessments}

The primary objective of both studies was to characterize the maximal effort pressure drop versus time profiles (inhaler-specific inhalation profiles) of participants. In Study 1 , inhalation profiles were measured via an instrumented ELLIPTA inhaler placed in a specially constructed instrumented blinding box that contained either a single-strip or a two-strip ELLIPTA inhaler with an empty blister. In Study 2, inhalation profiles were measured using disposable bespoke resistor components that mimicked the resistance of either a single-strip or two-strip ELLIPTA inhaler.

The following methodology was used in both studies. All participants performed up to three inhalations for each resistance level/configuration with sufficient time allowed between inhalations to ensure they were able to inhale at maximal effort. Participants were randomized to a sequence of resistance settings for their inhalation profile recordings using the RANDALL (GSK, Ware, UK) computerized randomization system. No investigational product or placebo was delivered.

The resulting inhaler-specific inhalation profiles were recorded using an Inhalation Profile Recorder (GSK, Ware, UK) and the profile with the highest pressure drop from each participant was taken as the best achieved by each subject and used in subsequent analyses. The endpoints for the characterization of the inhaler-specific inhalation profiles were peak pressure drop $(\mathrm{kPa})$, peak inspiratory flow rate (PIFR; L/min), inhaled volume (L), inhalation time (s), average inhalation flow rate $(\mathrm{L} / \mathrm{min})$, and, in Study 2 only, acceleration rate $(\mathrm{L} / \mathrm{min} / \mathrm{s})$ (data not reported).

In support of the primary objective, oropharyngeal geometry was recorded at Screening or during the study visit using a pharyngometer; pharyngometry endpoints were distance $(\mathrm{cm})$, volume $\left(\mathrm{cm}^{3}\right)$, and average cross-sectional area $\left(\mathrm{cm}^{2}\right)$. However, these pharyngometry data are not reported in this article due to issues identified with the GSK bespoke pharyngometry mouthpieces, which may have impacted the quality and accuracy of the data obtained. Further studies are required with the use of pharyngometry to fully understand how it can be applied to characterizing mouth and throat geometry in a way that has direct relevance to inhaler product development.

Inhaler-independent lung function was measured using spirometry, whole-body plethysmography, and diffusion. Spirometry assessments were performed at Screening and during the study visit to measure $\mathrm{FEV}_{1}, \mathrm{FVC}$, maximum expiratory flow rate at $25 \%$ and $50 \%$ FVC ( $\mathrm{V}_{\max 25}$ and $\mathrm{V}_{\text {max50, }}$, respectively), peak expiratory flow rate (PEFR), and PIFR. Whole-body plethysmography was performed during the study visit for the measurement of total lung capacity
(TLC), residual volume (RV), functional residual capacity (FRC), specific airways resistance $\left(\mathrm{sR}_{\mathrm{aw}}\right)$, and airways resistance $\left(\mathrm{R}_{\mathrm{aw}}\right)$; participants rested in the whole-body plethysmograph for at least 30 seconds prior to these assessments.

Diffusion was measured using the single breath method during the study visit and was used to assess alveolar volume (VA), diffusing capacity of the lung for carbon monoxide (DLCO), and Krogh factor (DLCO/VA). Post-study, it was investigated whether there were any strong correlations $(\mathrm{R}>0.7)$ between the inhaler-specific inhalation profiles and inhaler-independent lung function characteristics examined.

Data from high-resolution computed tomography (HRCT) scans were collected at two levels of lung inflation (FRC and TLC) for the investigation of exploratory endpoints, including fluid dynamics-based functional respiratory imaging measures of airway morphometry and function, which were used as inputs in the development of an in silico model for the prediction of regional lung deposition of the products delivered via the ELLIPTA DPI. HRCT scans were recorded during the study visit, using a 64-slice General Electric Lightspeed volume computed tomography (VCT) scanner (GE Healthcare, Little Chalfont, UK). The HRCT results will be published separately.

Safety assessments included physical examinations and a 12-lead electrocardiogram assessment of all participants at Screening, measurement of vital signs at Screening and during Visit 1, and clinical laboratory assessments for females only, to confirm either post-menopausal status at Screening, or a negative pregnancy test at Screening and during the study assessment visit (due to performance of HRCT scans). Adverse events (AEs) and serious AEs (SAEs) were also assessed at Screening, Visit 1, and follow-up.

Post-study, selected representative patient inhalation profiles were replicated in vitro using the eLung system and an anatomical throat model of average size to assess the dose-delivery characteristics of FF, FF/VI, UMEC, and UMEC/VI delivered via the ELLIPTA DPI. These results are presented in a separate publication (Hamilton et al., $\mathrm{J}$ Aerosol Med Pulm Drug Deliv, in press).

\section{Statistical analysis}

The primary analysis consisted of summarizing pharyngometry and the inhaler-specific inhalation parameters for healthy subjects and patients with asthma or COPD (stratified by severity) using descriptive summary statistics only. For very-severe COPD patients, data from patients in Study 1 and Study 2 were pooled and analyzed as described above. For this pooled analysis, very-severe COPD was defined according to the inclusion criteria for Study 2; therefore, data from two patients in the very-severe COPD subgroup in Study 1 were excluded because they did not conform to this definition. However, data from the remaining three verysevere patients from Study 1 were included.

The maximum of the triplicate readings for peak pressure drop were used to calculate summary statistics for all inhalation endpoints by resistance setting. No formal hypothesis testing was conducted. Sample sizes of 105 subjects (15 healthy subjects, 45 patients with asthma, and 45 patients with COPD) for Study 1 and 15 COPD patients for Study 2 were based on feasibility.

It was felt that inhaler-specific PIFR and inhaled volume were key clinical characteristics of the inhalation profiles, 
and that statistical analysis would assist with interpretation of the results. Post hoc statistical analyses of these parameters were conducted using an Analysis of Variance model, including disease state as a factor. Least-squares means and their $95 \%$ confidence intervals (CIs) for each subgroup were estimated. If the analysis identified a disease severity subgroup effect, then pre-specified comparisons of interest between the disease severity subgroups and their associated 95\% CIs and $p$-values were derived using estimates from the same model, including Bonferroni Step Down adjustments for multiple comparisons.

Post-completion of the clinical study report for Study 1, analyses of linear correlations were calculated using data from all patients, using Pearson correlation coefficients to compare inhaler-specific inhalation characteristics (including peak pressure drop, PIFR, and inhaled volume) with inhalerindependent variables (including BMI, height, weight, $\mathrm{FEV}_{1}$, FVC, PEFR, PIFR, TLC, RV, FRC, $\mathrm{R}_{\mathrm{aw}}$, VA, DLCO, and Krogh factor).

For the clinical study report of Study 2, pre-planned correlation analyses as outlined above were conducted using the combined data from both studies. Additional post hoc exploratory analyses were then considered to be needed on scientific grounds for asthma patients only and for COPD patients only as, from a clinical perspective, it was felt that there is no clinical relevance in healthy subjects' results and, in addition, not all products are targeted for both asthma and COPD, as the extent of disease severity may have a different impact on asthma than on COPD. These analyses were used to calculate correlation $\mathrm{R}$-values and $p$-values.

\section{Results}

105 participants were included in Study $1(n=15$ healthy subjects, $n=45$ asthma patients, $n=45$ COPD patients) and 15 in Study 2. The characteristics of all 120 participants are summarized in Table 1. We report the pooled results for the very-severe COPD patients $(n=18$; three patients from Study 1 who met the Study 2 criteria of post-bronchodilator $\mathrm{FEV}_{1}<30 \%$ predicted; 15 patients from Study 2), unless otherwise stated. The largest differences observed between cohorts (healthy, asthma, and COPD) and disease severity subgroups included in the pooled analysis are highlighted in the following sections.

\section{Inhaler-specific inhalation parameters}

In the pooled analysis, mean maximal effort PIFR varied from 71.1-110.6 L/min (range: 41.6-142.9 L/min). The mean [range] PIFR for the very-severe COPD subgroup in the pooled analysis was $71.1 \mathrm{~L} / \mathrm{min}$ [41.6-104.8] $\mathrm{L} / \mathrm{min}$ ) for the resistance of the single-strip configuration and $65.8 \mathrm{~L} / \mathrm{min}$ (range: $43.5-94.1 \mathrm{~L} / \mathrm{min}$ ) for the resistance of the two-strip configuration. The lowest PIFR measurements were recorded in very-severe COPD patients, and the highest mean PIFRs were achieved by patients with moderate asthma for both of the resistances (Table 2).

The mean maximal effort PIFRs achieved were slightly higher for the one-strip configuration, but as the 95\% CIs overlapped and the differences were small, this was not considered to be clinically relevant. As results for all other inhalation endpoints were also similar between both configurations of the inhaler, we report only the results relevant to

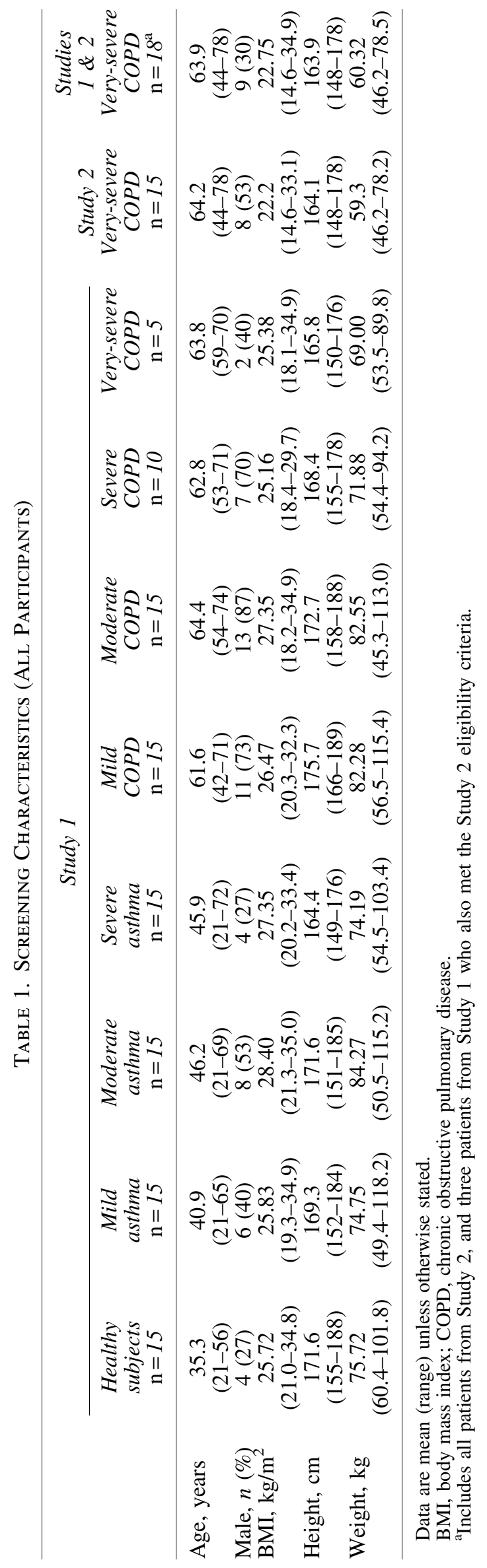


Table 2. PIFR (L/Min) For Single- and Two-Strip Configurations of the ELLiPTA DPI (All Participants)

\begin{tabular}{llrl}
\hline Study & \multicolumn{1}{c}{ Disease state } & Mean $(95 \%$ CI $)$ & Range \\
\hline $\begin{array}{l}\text { Single-strip configuration } \\
1\end{array}$ & & & $79.3-142.9$ \\
& Healthy subjects & & $79.6-135.8$ \\
& Mild asthma & $105.1(95.9,114.4)$ & $72.3-136.9$ \\
& Moderate asthma & $106.3(97.7,114.9)$ & $71.2-133.1$ \\
& Severe asthma & $110.6(102.0,119.3)$ & $75.2-128.9$ \\
& Mild COPD & $103.2(94.2,112.2)$ & $63.2-117.4$ \\
& Moderate COPD & $101.9(92.5,11.4)$ & $72.3-121.6$ \\
& Severe COPD & $97.2(88.5,105.8)$ & $41.6-83.3$ \\
2 & Very-severe COPD & $88.0(76.9,99.0)$ & $43.4-104.8$ \\
$1 \& 2$ & Very-severe COPD & $67.5(47.2,87.8)$ & $41.6-104.8$ \\
Two-strip configuration & Very-severe COPD & $72.6(62.7,82.6)$ & \\
1 & & $71.1(62.1,80.1)$ & $74.4-131.7$ \\
& Healthy subjects & & $73.7-122.2$ \\
& Mild asthma & $98.3(89.7,107.0)$ & $67.4-129.9$ \\
& Moderate asthma & $97.9(89.3,106.4)$ & $72.4-124.6$ \\
& Severe asthma & $103.2(95.2,111.1)$ & $74.2-123.6$ \\
& Mild COPD & $96.6(88.5,104.7)$ & $60.0-104.8$ \\
& Moderate COPD & $95.7(87.0,104.4)$ & $63.0-116.9$ \\
& Severe COPD & $91.1(83.8,98.4)$ & $43.5-81.0$ \\
$1 \& 2$ & Very-severe COPD & $83.0(71.3,94.8)$ & $45.0-94.1$ \\
& Very-severe COPD & $66.5(48.6,84.4)$ & $43.5-94.1$ \\
\hline
\end{tabular}

CI, confidence interval; COPD, chronic obstructive pulmonary disease; DPI, dry powder inhaler; PIFR, peak inspiratory flow rate.

${ }^{a}$ Includes all patients from Study 2, and three patients from Study 1 who also met the Study 2 eligibility criteria.

the two-strip configuration in full within this publication. The results and conclusions drawn are applicable to either configuration.

\section{Peak pressure drop, PIFR, and inhaled volume (Fig. 1)}

A numerically lower mean peak pressure drop was recorded for patients with moderate, severe, and very-severe COPD, when compared with other participants; these values decreased further with increasing COPD severity. The largest difference in mean peak pressure drop between adjacent subgroups was $2.3 \mathrm{kPa}$ (39\%), and was observed in the COPD group between severe and very-severe patients.

Post hoc analysis comparing PIFR values for healthy subjects and asthma patients found no statistically significant difference $(-0.9 \mathrm{~L} / \mathrm{min}$ [95\% CI: $-13.95,12.20], p>0.999)$. However, patients from both of these groups had a statistically significantly greater PIFR versus COPD patients (healthy subjects: $+14.4 \mathrm{~L} / \mathrm{min}[1.67,27.20], p=0.010$; asthma patients: $+15.3 \mathrm{~L} / \mathrm{min}[6.50,24.11], p<0.001)$. In asthma patients, there was no statistically significant trend in PIFR as disease severity increased. In COPD patients, there was a linear trend for PIFR to decrease as disease severity increased $(p<0.001)$; between subgroups, PIFR values for mild, moderate, and severe COPD patients were statistically significantly greater when compared with very-severe patients $(+29.9 \mathrm{~L} / \mathrm{min}[14.55,45.21]$, $p<0.001 ;+25.2 \mathrm{~L} / \mathrm{min}[9.92,40.58], p<0.001 ;+17.2 \mathrm{~L} / \mathrm{min}$ $[-0.09,34.51], p=0.034$, respectively).

For inhaled volume measurements, no statistically significant differences between healthy subjects and either asthma or COPD patients were identified $(-0.1$ L $[-0.68,0.44]$, $p>0.999 ; 0.4[-0.14,0.96], p=0.231$, respectively); however, there was a statistically significant difference between asthma and COPD patients $(+0.5 \mathrm{~L}[0.15,0.91], p<0.001)$.
There was a linear trend towards decreasing inhaled volume as COPD severity increased from mild to very-severe $(p<0.001)$, and inhaled volumes were statistically significantly greater in patients with mild versus severe $(+1.0 \mathrm{~L}$ $[0.24,1.79], p=0.002)$ or very-severe $(+1.4 \mathrm{~L}[0.74,2.06]$, $p<0.001)$ COPD and with moderate versus very-severe COPD (1.1 L [0.44, 1.76], $p<0.001)$.

\section{Inhalation time(s) and average inhalation flow rate}

Results did not differ markedly between healthy subjects and patients with asthma, regardless of disease severity. Mean inhalation time (time to maximal capacity) was slightly longer in patients with mild COPD (3.0 s; range: $2.21-4.26 \mathrm{~s}$ ), while shorter mean inhalation times were demonstrated by severe (2.1 s; range: 1.45-3.05 s) and very-severe COPD patients (2.1 s; range: $1.40-3.62 \mathrm{~s})$ compared with all other participants (mean: 2.3-2.7 s). Mean average inhalation flow rate was also lower in COPD patients (39.7-54.9 L/min; range: $28.7-90.1 \mathrm{~L} / \mathrm{min})$ than in healthy subjects $(63.8 \mathrm{~L} / \mathrm{min}$; range: $48.0-78.0 \mathrm{~L} / \mathrm{min})$ or patients with asthma $(59.8-64.7$ L/min; range: 40.4-86.8 L/min), and decreased further with increasing COPD disease severity.

\section{Inhaler-independent spirometry parameters (Table 3)}

Mean $\mathrm{FEV}_{1}$, PEFR, $\mathrm{V}_{\max 25}$, and $\mathrm{V}_{\max 50}$ differed between healthy subjects, asthma patients, and COPD patients, corresponding to the presence and severity of disease. In COPD patients, mean $\mathrm{FEV}_{1}$ and FVC was lower by $2.35 \mathrm{~L}(81 \%)$ and $2.50 \mathrm{~L}(56 \%)$, respectively, between mild and very-severe COPD patients. PIFR was not notably different between healthy subjects and asthma patients, regardless of disease severity, and also patients with mild or moderate COPD. However, mean PIFR was lower in the severe and very-severe COPD patients, 
a

Mean $(95 \% \mathrm{Cl})$

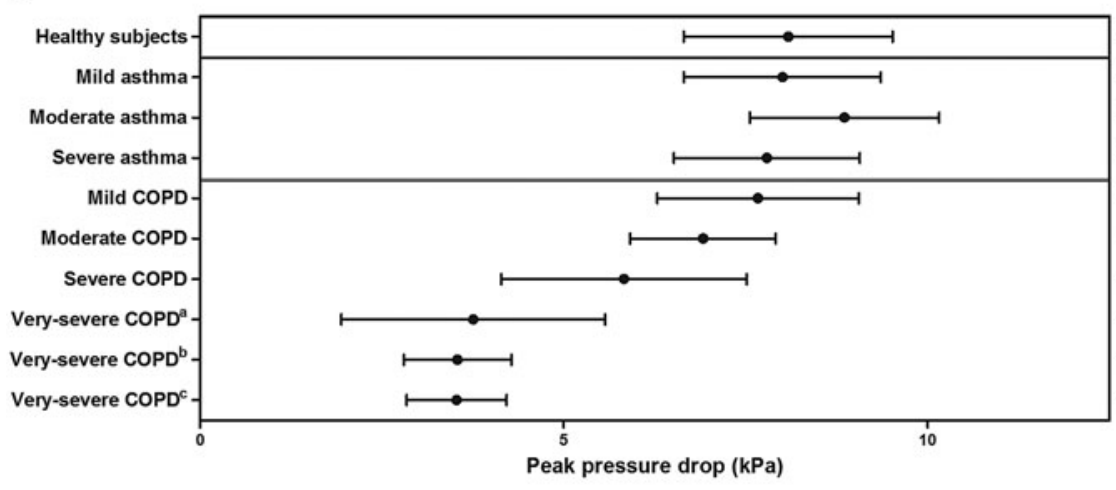

b

Mean $(95 \% \mathrm{Cl})$

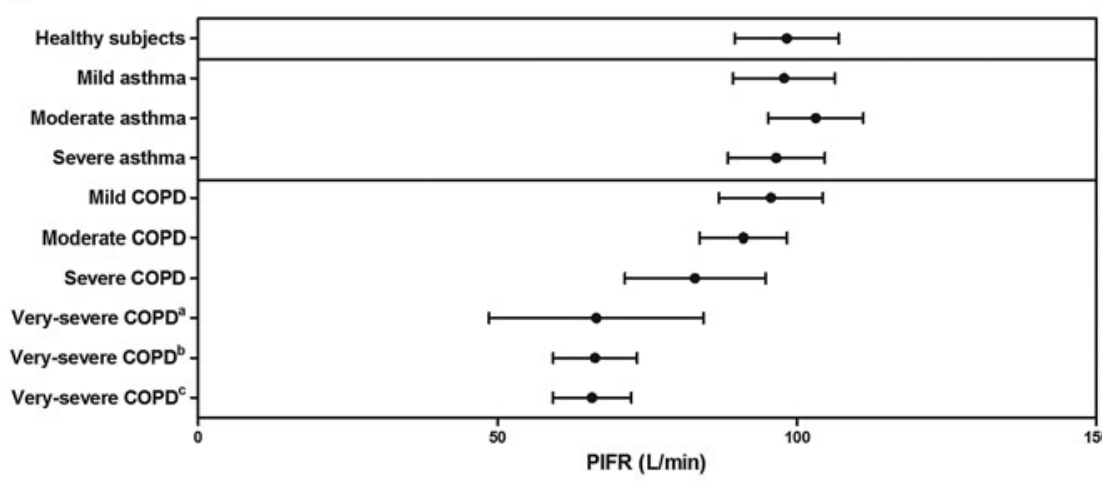

c

Mean $(95 \% \mathrm{Cl})$

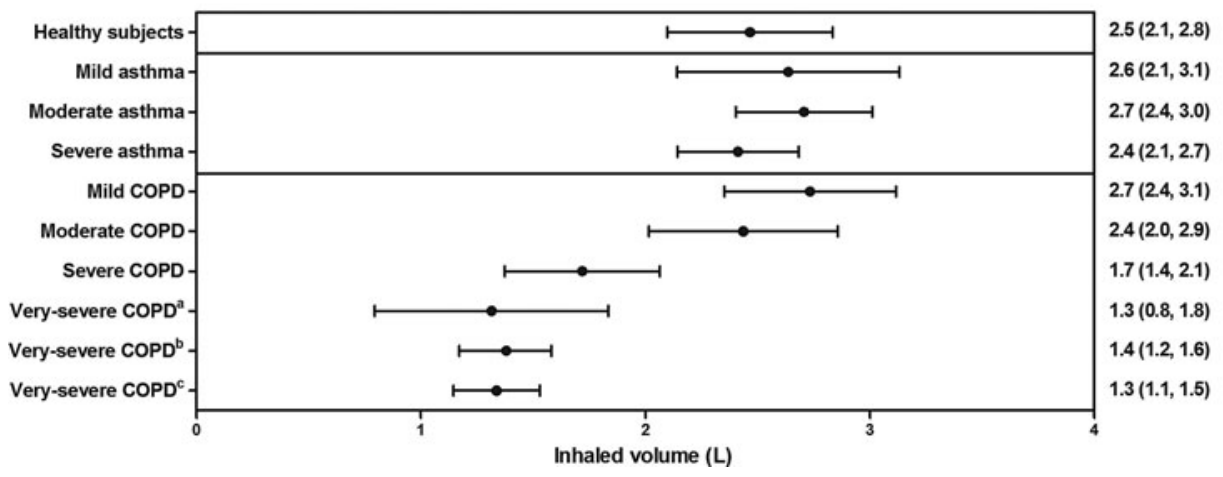

FIG. 1. (a) Mean (95\% CI) peak pressure drop, (b) mean (95\% CI) PIFR, and (c) mean (95\% CI) inhaled volume (all patients). CI, confidence interval; COPD, chronic obstructive

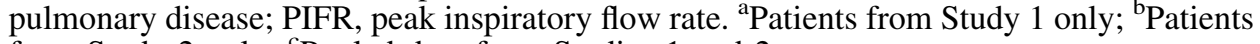
from Study 2 only; ${ }^{\mathrm{c}}$ Pooled data from Studies 1 and 2.

and tended to decrease with increasing disease severity; mean PIFR was $215.1 \mathrm{~L} / \mathrm{min}$ (52\%) lower in the very-severe COPD group when compared with the mild COPD group.

\section{Inhaler-independent plethysmography and diffusion parameters (Table 4)}

Patients with asthma generally demonstrated slightly increased values for all plethysmography parameters when compared with healthy subjects, although little variation was seen between the different severities of asthma. COPD patients generally demonstrated increased mean TLC, RV, FRC, airways resistance, and specific airways resistance compared with healthy subjects and asthma patients, all of which tended to increase with COPD severity. For the alveolar volume measurements, only very-severe COPD patients demonstrated a markedly different mean value (4.0 L; range: $3.0-4.6)$ compared with healthy subjects $(5.4 \mathrm{~L}$; range: $3.8-7.3)$.

Decreases in DLCO were observed with both increasing asthma and COPD disease severity, compared with healthy subjects and mild asthma patients; DLCO measurements were lowest in the COPD cohort. A decrease in mean DLCO of $5.6 \mathrm{mmol} / \mathrm{min} . \mathrm{kPa}(75 \%)$ was observed between mild and very-severe COPD patients. Similar trends were observed for Krogh factor across the asthma and COPD cohorts, compared with healthy subjects. 


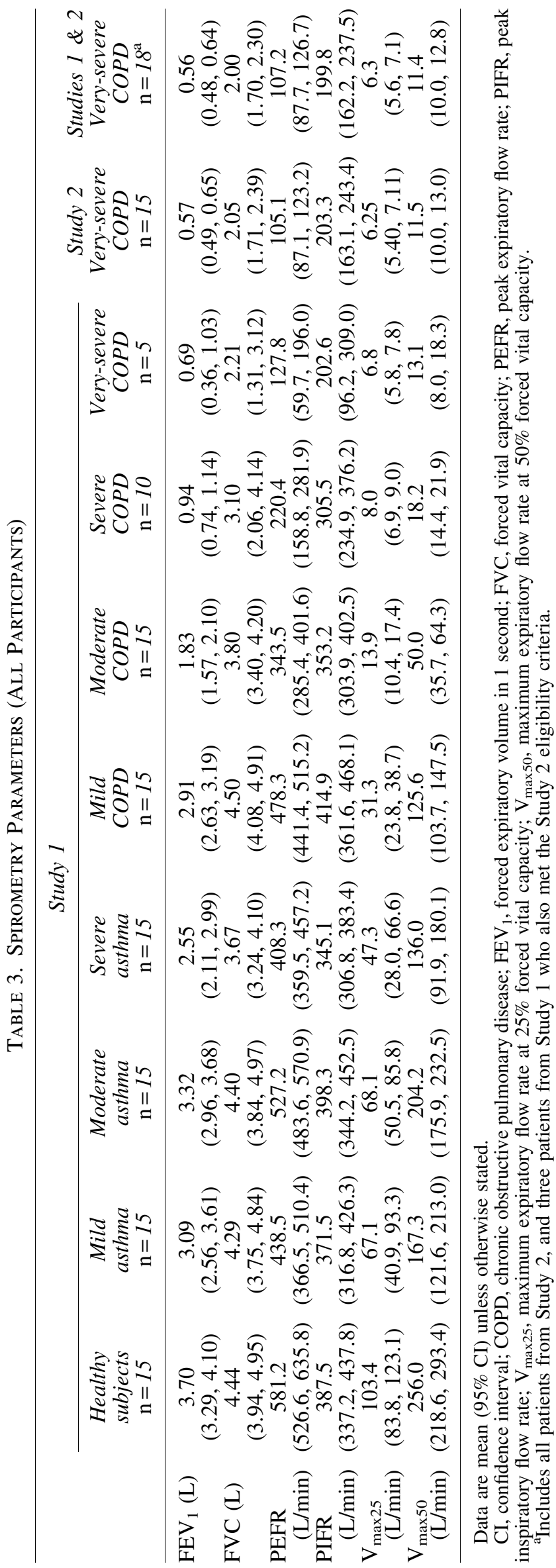

\section{Post-study analyses of linear correlations (Table 5)}

Across all participants, there were strong correlations $(\mathrm{R}>0.7)$ that were statistically significant $(p<0.05)$ between the following inhaler-specific inhalation characteristics versus inhaler-independent inhalation characteristics: PIFR (inhalerspecific) versus PEFR, PIFR, and DLCO; inhaled volume versus $\mathrm{FEV}_{1}, \mathrm{FVC}$, alveolar volume, and DLCO. In the asthma cohort none of the correlations were strong $(\mathrm{R}>0.7)$; however, statistically significant moderate correlations $(\mathrm{R} \geq 0.49)$ were observed for PIFR (inhaler-specific) versus $\mathrm{FEV}_{1}$, PEFR, PIFR, and DLCO, and for inhaled volume (inhaler-specific) versus $\mathrm{FEV}_{1}, \mathrm{FVC}$, alveolar volume, and DLCO. For COPD patients, there were statistically significant strong correlations between PIFR (inhaler-specific) versus $\mathrm{FEV}_{1}$, PEFR, PIFR, and DLCO, and for inhaled volume (inhaler-specific) versus $\mathrm{FEV}_{1}, \mathrm{FVC}$, alveolar volume, and DLCO (Table 5; Fig. 2; Supplementary Fig. S1).

\section{Safety}

The incidence of AEs was low and no individual AE was reported by more than one participant. Two serious AEs were reported by one patient in the very-severe COPD subgroup (chronic respiratory failure and pathogen resistance); the investigator considered there to be no reasonable possibility that these were related to study participation.

\section{Discussion}

These studies characterized the maximal effort inhalation profiles of healthy subjects, patients with asthma, and patients with COPD through a DPI of moderate resistivity, the ELLIPTA inhaler. It was found that, generally, inhalerspecific inhalation endpoints were broadly similar across healthy subjects, asthma patients (regardless of disease severity), and patients with mild COPD. However, compared with other participants, patients with moderate to verysevere COPD demonstrated decreased inhalation capability across various parameters, which tended to decrease further with increasing disease severity.

There are several possible explanations for this finding. First, respiratory muscle function is often compromised in COPD patients due to hyperinflation, hypoxemia, and muscle wasting, which may lead to decreased PIFR. ${ }^{(19)}$ Second, respiratory muscle strength, expiratory flow rates, and maximal inspiratory flow rates are known to decrease with age, ${ }^{(20)}$ and the mean age of COPD patients (63.3 years; range: $42-78$ ) was greater than that of healthy subjects ( 35.3 years; range: 21-56) and of asthma patients (44.3 years; range: $21-72$ ).

In another study that compared inspiratory flow rates across different DPIs between elderly COPD patients and age-matched healthy controls, the PIFR achieved through DPIs significantly reduced with increasing age, but no difference in the ability to achieve acceptable flows using the DPIs tested was observed between the two groups. ${ }^{(21)}$ This suggests that age may account for some of the inhalation profile differences observed between the COPD patients and other participants.

Despite the observed differences in the inhaler-specific inhalation profiles between the cohorts and disease severity subgroups in these studies, all participants were able to generate a PIFR of $\geq 41.6 \mathrm{~L} / \mathrm{min}$ through the single-strip 


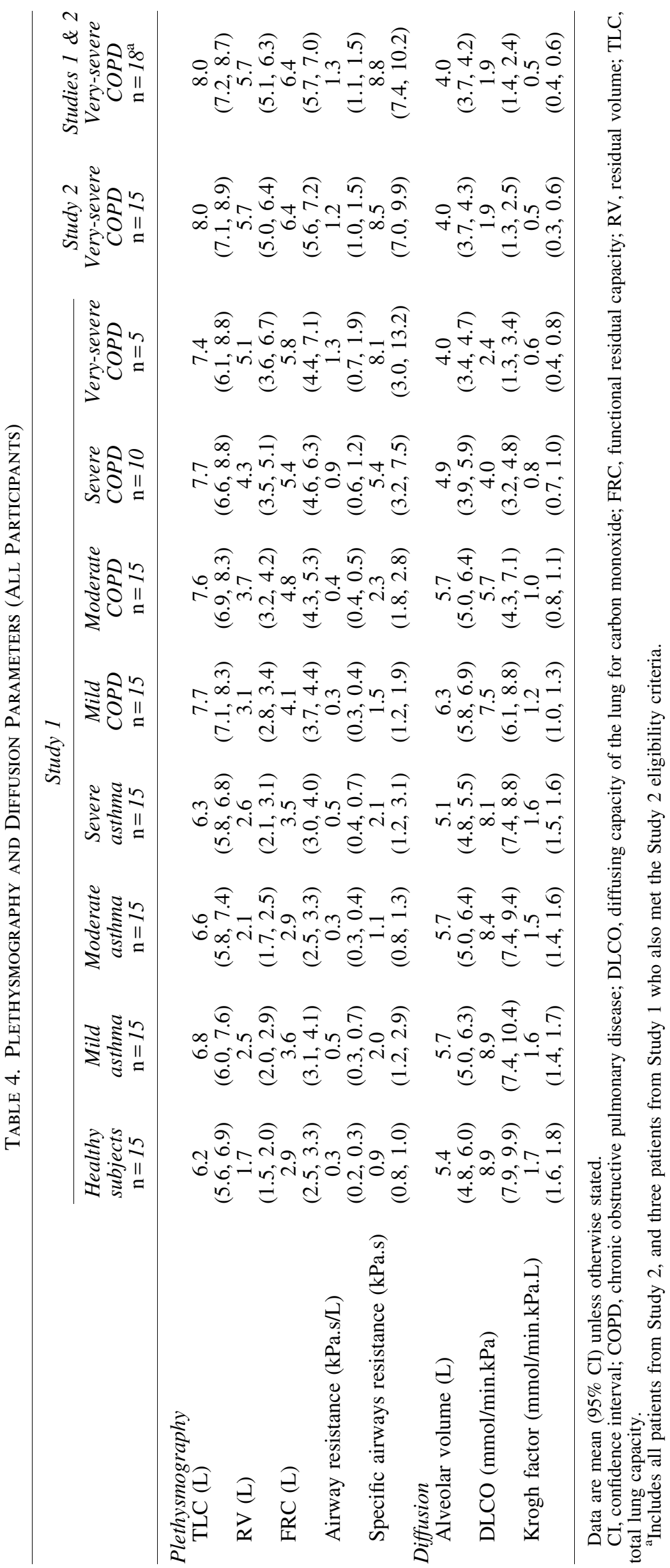


Table 5. Correlations Between Inhaler-Specific And InHaler-IndePendent Inhalation Characteristics (All Participants)

\begin{tabular}{|c|c|c|c|c|}
\hline Data genre & Variable & Peak pressure drop & PIFR (Inhaler) & Inhaled volume \\
\hline \multicolumn{5}{|l|}{ All participants } \\
\hline \multirow[t]{4}{*}{ Spirometry } & $\mathrm{FEV}_{1}$ & - & $0.69(p<0.0001)$ & $0.73(p<0.0001)$ \\
\hline & $\mathrm{FVC}$ & - & - & $0.80(p<0.0001)$ \\
\hline & PEFR & - & $0.76(p<0.0001)$ & - \\
\hline & PIFR (spirometry) & - & $0.80(p<0.0001)$ & - \\
\hline \multirow[t]{4}{*}{ Whole-body plethysmography } & FRC & - & - & $-0.29(p=0.0013)$ \\
\hline & Residual volume & - & - & $-0.39(p<0.0001)$ \\
\hline & TLC & - & $0.02(p=0.8453)$ & $0.23(p=0.0104)$ \\
\hline & $\mathrm{R}_{\mathrm{AW}}$ & $-0.55(p<0.0001)$ & - & - \\
\hline \multirow[t]{3}{*}{ Diffusion } & VA & - & - & $0.76(p<0.0001)$ \\
\hline & DLCO & - & $0.71(p<0.0001)$ & $0.74(p<0.0001)$ \\
\hline & Krogh factor & - & $0.59(p<0.0001)$ & $0.48(p<0.0001)$ \\
\hline \multicolumn{5}{|l|}{ Asthma patients } \\
\hline \multirow[t]{4}{*}{ Spirometry } & $\mathrm{FEV}_{1}$ & - & $0.52(p=0.0003)$ & $0.60(p<0.0001)$ \\
\hline & $\mathrm{FVC}$ & - & & $0.62(p<0.0001)$ \\
\hline & PEFR & - & $0.66(p<0.0001)$ & \\
\hline & PIFR (spirometry) & - & $0.69(p<0.0001)$ & \\
\hline \multirow[t]{4}{*}{ Whole-body plethysmography } & FRC & - & & $0.15(p=0.3344)$ \\
\hline & Residual volume & - & & $-0.08(p=0.5947)$ \\
\hline & TLC & - & $0.25(p=0.1021)$ & $0.44(p=0.0026)$ \\
\hline & $\mathrm{R}_{\mathrm{AW}}$ & $-0.21(p=0.1589)$ & & \\
\hline \multirow[t]{3}{*}{ Diffusion } & VA & - & & $0.56(p<0.0001)$ \\
\hline & DLCO & - & $0.49(p=0.0007)$ & $0.64(p<0.0001)$ \\
\hline & Krogh factor & - & $0.30(p=0.0436)$ & $0.23(p=0.1326)$ \\
\hline \multicolumn{5}{|l|}{ COPD patients ${ }^{\mathrm{a}}$} \\
\hline \multirow[t]{4}{*}{ Spirometry } & $\mathrm{FEV}_{1}$ & - & $0.73(p<0.0001)$ & $0.84(p<0.0001)$ \\
\hline & FVC & - & - & $0.85(p<0.0001)$ \\
\hline & PEFR & - & $0.80(p<0.0001)$ & - \\
\hline & PIFR (spirometry) & - & $0.85(p<0.0001)$ & - \\
\hline \multirow[t]{4}{*}{ Whole-body plethysmography } & FRC & - & - & $-0.29(p=0.0289)$ \\
\hline & Residual volume & - & - & $-0.40(p=0.0018)$ \\
\hline & TLC & - & $0.27(p=0.0398)$ & $0.39(p=0.0022)$ \\
\hline & $\mathrm{R}_{\mathrm{AW}}$ & $-0.65(p<0.0001)$ & - & - \\
\hline \multirow[t]{3}{*}{ Diffusion } & VA & - & - & $0.88(p<0.0001)$ \\
\hline & DLCO & - & $0.79(p<0.0001)$ & $0.84(p<0.0001)$ \\
\hline & Krogh factor & - & $0.67(p<0.0001)$ & $0.65(p<0.0001)$ \\
\hline
\end{tabular}

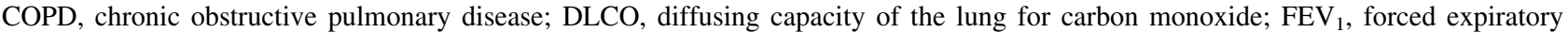
volume in 1 second; FRC, functional residual capacity; FVC, forced vital capacity; PEFR, peak expiratory flow rate; PIFR, peak inspiratory flow rate; $\mathrm{R}_{\mathrm{AW}}$, airways resistance; TLC, total lung capacity; VA, alveolar volume.

${ }^{\mathrm{a}}$ Includes all COPD patients from Study 1 and Study 2. Values in bold showed strong correlation $(\mathrm{R}>0.7)$ and are statistically significant $(p<0.05)$.

ELLIPTA DPI (or equivalent), or $\geq 43.5 \mathrm{~L} / \mathrm{min}$ via the twostrip (or equivalent) configuration; the lowest PIFRs were achieved in the very-severe COPD subgroups. PIFR is an important inhalation profile parameter because of its direct influence on the dose delivery from most DPIs. ${ }^{(19)}$ However, previous in vitro assessments, under standard impactor conditions, have shown that the dose delivery characteristics of products delivered via the ELLIPTA inhaler were consistent for flow rates ranging from 30 to $90 \mathrm{~L} / \mathrm{min}$ (Grant et al., submitted in parallel); this range encompasses the patients in these studies who generated the lowest inspiratory efforts of at least $41.6 \mathrm{~L} / \mathrm{min}$.

Furthermore, data from Phase III clinical trials, in which treatment efficacy of FF/VI, ${ }^{(22,23)}$ and UMEC and UMEC/ $\mathrm{VI}^{(24-26)}$ has been demonstrated even in severe to very-severe COPD patients, suggest that the inhalation efforts achieved by these patients are sufficient to use the ELLIPTA inhaler.
This suggestion is further supported by assessments of the in vitro dosing performance of the ELLIPTA inhaler using the patient-specific inhalation profiles generated in the present studies; these data are reported separately (Hamilton et al., submitted in parallel).

Spirometry, whole-body plethysmography, and diffusion capacity results were consistent with expectations for the recruited populations of healthy subjects, asthma patients, and COPD patients. Mean values for plethysmography measures generally increased with increasing severity of COPD, which is likely to indicate the presence of hyperinflation in some patients. Analysis of correlations between spirometry, plethysmography, and diffusion parameters and the inhaler-specific endpoints identified statistically significant strong correlations when all participants were pooled. However, when analyzed separately by disease, statistically significant strong correlations were only identified in the 

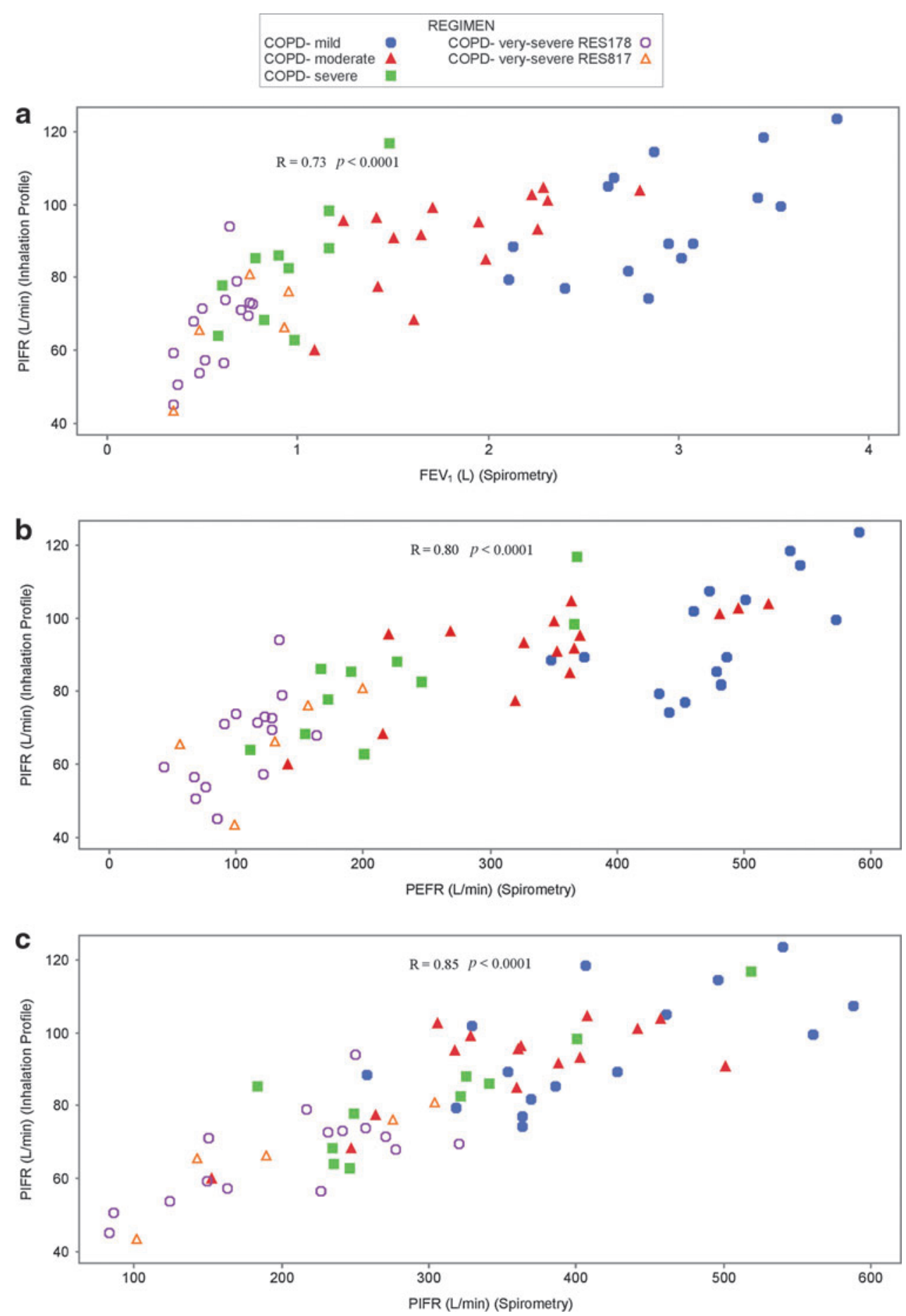

FIG. 2. Correlation figures for COPD patients only for (a) PIFR (via the ELLIPTA DPI) versus FEV $_{1}$ (spirometry), (b) PIFR (via the ELLIPTA DPI) versus PEFR (spirometry), and (c) PIFR (via the ELLIPTA DPI) versus PIFR (spirometry). COPD, chronic obstructive pulmonary disease; DLCO, diffusing capacity of the lung for carbon monoxide; DPI, dry powder inhaler; $\mathrm{FEV}_{1}$, forced expiratory volume in 1 second; FVC, forced vital capacity; PEFR, peak expiratory flow rate; PIFR, peak inspiratory flow rate.

COPD cohort, suggesting that the strong correlation observed for all participants was driven by this cohort.

Although further investigation is required, these preliminary findings suggest that some inhaler-independent inhalation characteristics (i.e., FEV 1 , FVC, PEFR, PIFR, alveolar vol- ume, and DLCO) may provide a useful indication of the inhalation parameters that COPD patients can achieve through a DPI of known resistivity, and therefore whether that DPI may be suitable for individual patients with COPD. In the asthma cohort, correlations were not as strong, but the identification of 
some statistically significant moderate correlations suggests that this may also be true for asthma patients, although further studies would be required to improve the reliability of any application of these results in asthma patients.

These studies examined the relationship between lung function and inhalation profiles through the moderate resistivity of the ELLIPTA DPI in healthy subjects, asthma patients, and COPD patients. The observations and conclusions may not be equally applicable to all other DPIs, especially those that do not have similar resistivity. However, the mean PIFR values observed in these studies for the ELLIPTA device were comparable to reported values for the DISKUS ${ }^{\circledR}$ DPI, ${ }^{(27)}$ which has similar resistance. In the DISKUS study by Broeders et al., ${ }^{(27)}$ asthmatic patients and those with mild, moderate, or severe COPD achieved PIFRs of $111.4,107.8,91.8$, and $95.9 \mathrm{~L} / \mathrm{min}$, respectively; all values falling within the $95 \%$ CIs of the corresponding patient cohorts using the single-strip ELLIPTA inhaler in the present studies (Table 2).

It should be noted that the maximal effort inhalation profiles recorded in the present studies do not correspond to the 'long, steady, and deep' inhalation instruction provided in the patient information leaflet for the ELLIPTA inhaler. The use of a maximal effort inhalation was necessary in this study to maximize the chances of identifying any relevant correlations between the inhaler-specific and inhalerindependent inhalation profiles. The 'long, steady, and deep' inhalation instruction may allow greater scope for interpretation and, consequently, the inhalation effort applied may vary more markedly from patient to patient. It would therefore be valuable to conduct further studies using the 'long, steady, and deep' instruction to determine if this has any effect on patients' inhalation characteristics and, consequently, drug delivery.

A study that examined the effect of two different instructions ('slow, deep' and 'fast, forceful') on the PIFR achieved through the Handihaler ${ }^{\circledR}$ device found that this resulted in a mean offset of approximately $15 \mathrm{~L} / \mathrm{min}$ between the two. ${ }^{(28)}$ We also acknowledge that there were other limitations of these studies, including a relatively small number of patients, and an imbalance of gender and age. Further studies of this type would be useful to establish the generalizability of these findings. It is recognized that the inhalation profile information is most useful when combined with knowledge of the product performance across the full range of patient relevant flow rates and volumes, which are described elsewhere (Hamilton et al., J Aerosol Med Pulm Drug Deliv, in press).

\section{Conclusions}

These studies indicate that patients with asthma can achieve similar inhaler-specific inhalation profiles compared with healthy subjects when inhaling with maximal effort through a moderate-resistance DPI, such as the ELLIPTA inhaler. Increasing COPD severity may reduce the patients' inhalation capability; however, COPD patients were still able to achieve PIFRs ranging from 41.6 to $128.9 \mathrm{~L} / \mathrm{min}$. Additionally, inhaler-specific inhalation parameters were found to correlate to some well-established inhalerindependent lung function measurements within the COPD cohort including $\mathrm{FEV}_{1}, \mathrm{FVC}$, PEFR, and PIFR, suggesting that lung function parameters may be useful indicators of a patient's ability to inhale efficiently through a moderateresistance DPI.

\section{Acknowledgments}

These studies were funded by GSK, study numbers: RES113817 (clinicaltrials.gov NCT01345266); RES117178 (NCT02076269).

All authors meet the criteria for authorship set forth by the International Committee for Medical Journal Editors.

D. Prime, W. de Backer, M. Hamilton, A. Cahn, A. Preece, D. Kelleher, A. Moore, and N. Brealey were involved in the conception and design of these studies, and the interpretation of data. W. de Backer was involved in the acquisition of data. D. Prime, W. de Backer, M. Hamilton, D. Kelleher, and J. Moynihan were involved in data analysis. For Study 2 (RES113178) only, A. Baines was involved in the conception and design of the study, acquisition of data, data analysis, and interpretation of the data. Inhalation profiles were recorded at the Antwerp University Hospital, Antwerp, Belgium, and results were returned to GSK (Inhaled Delivery Science Department) for analysis and interpretation.

The authors acknowledge the late Dr. Patricia KP Burnell, Emma Lindo, and members of the RES113817 and RES117178 clinical study teams, and Mike Aylott, BSc, MSc, and Kavita Peddiraju, MA, formerly of GSK, for their contributions to previous drafts of this manuscript. Editorial support for development of early drafts of this manuscript, in the form of development of the manuscript first draft, editorial suggestions to draft versions of this paper, assembling tables and figures, collating author comments, and referencing was provided by Diana Jones of Cambrian Clinical Associates Ltd. and was funded by GSK.

Editorial support in the form of development of final drafts of this manuscript in consultation with the authors, editorial suggestions to draft versions of this article, assembling tables and figures, collating author comments, copyediting, fact checking, referencing, and graphic services was provided by Jacqueline Phillipson, $\mathrm{PhD}$, and Laura Maguire, MChem, at Gardiner-Caldwell Communications (Macclesfield, UK) and was funded by GSK.

\section{Author Disclosure Statement}

D. Prime, M. Hamilton, A. Cahn, A. Preece, D. Kelleher, A. Baines, A. Moore, and N. Brealey are employees of and hold stock in the study sponsor, GSK. J. Moynihan is an employee of Synergy, contracted to the study sponsor, GSK. W. DeBacker has no conflicts to declare.

\section{References}

1. Atkins PJ: Dry powder inhalers: An overview. Respir Care. 2005;50:1304-1310.

2. Berger W: Aerosol devices and asthma therapy. Curr Drug Deliv. 2009;6:38-49.

3. Ari A, and Fink JB: Guidelines for aerosol devices in infants, children and adults: Which to choose, why and how to achieve effective aerosol therapy. Expert Rev Respir Med. 2011;5:561-572.

4. Fink JB, Colice GL, and Hodder R: Inhaler devices for patients with COPD. COPD. 2013;10:523-535. 
5. Ganderton D: General factors influencing drug delivery to the lung. Respir Med. 1997;91:13-16.

6. Bronsky EA, Grossman J, Henis MJ, Gallo PP, Yegen U, Della Cioppa G, Kottakis J, and Mehra S: Inspiratory flow rates and volumes with the Aerolizer dry powder inhaler in asthmatic children and adults. Curr Med Res Opin. 2004; 20:131-137.

7. Clark AR, and Hollingworth AM: The relationship between powder inhaler resistance and peak inspiratory conditions in healthy volunteers-implications for in vitro testing. $\mathbf{J}$ Aerosol Med. 1993;6:99-110.

8. Riley JH, Tabberer MM, Richard N, Donald AC, Church A, and Harris SS: Use of a new dry powder inhaler to deliver umeclidinium/vilanterol in the treatment of COPD. Eur Respir J. 2013;42:880s.

9. Svedsater H, Dale P, Garrill K, Walker R, and Woepse MW: Qualitative assessment of attributes and ease of use of the ELLIPTA ${ }^{\mathrm{TM}}$ dry powder inhaler for delivery of maintenance therapy for asthma and COPD. BMC Pulm Med. 2013;13:72.

10. Svedsater H, Jacques L, Goldfrad C, and Bleecker ER: Ease of use of the ELLIPTA dry powder inhaler: Data from three randomised controlled trials in patients with asthma. NPJ Prim Care Respir Med. 2014;24:14019.

11. Laube BL, Janssens HM, de Jongh FHC, Devadason SG, Dhand R, Diot P, Everard ML, Horvath I, Navalesi P, Voshaar T, and Chrystyn H: What the pulmonary specialist should know about the new inhalation therapies. ERS/ISAM Task Force report. Eur Respir J. 2011;37:1308-1331.

12. Bisgaard H, Klug B, Sumby BS, and Burnell PK: Fine particle mass from the Diskus inhaler and Turbuhaler inhaler in children with asthma. Eur Respir J. 1998;11: 1111-1115.

13. Burnell PKP, Small T, Doig S, Johal B, Jenkins R, and Gibson GJ: Ex-vivo product performance of Diskus and Turbuhaler inhalers using inhalation profiles from patients with severe chronic obstructive pulmonary disease. Respir Med. 2001;95:324-330.

14. International Conference on Harmonisation of Technical Requirements for Registration of Pharmaceuticals for $\mathrm{Hu}-$ man Use: ICH Harmonised Tripartite Guideline. Guideline for Good Clinical Practice E6(R1). Available at http://www .ich.org/fileadmin/Public_Web_Site/ICH_Products/Guidelines/ Efficacy/E6/E6_R1_Guideline.pdf. Accessed February 19, 2015.

15. World Medical Association Declaration of Helsinki: Ethical Principles for Medical Research Involving Human Subjects. Last updated 2008. Available at http://www.wma .net/en/30publications/10policies/b3/17c.pdf. Accessed February 19, 2015.

16. British Thoracic Society Scottish Intercollegiate Guidelines Network. British Guideline on the Management of Asthma. Thorax. 2008;63:iv1-iv121.

17. Global Initiative for Chronic Obstructive Lung Disease: Global strategy for the diagnosis, management, and prevention of chronic obstructive pulmonary disease. Updated December 2007. Available at http://www.goldcopd.org/Guidelines/ guidelines-global-strategy-for-diagnosis-management-2007-3 .html. Accessed February 19, 2015.

18. Global Initiative for Chronic Obstructive Lung Disease: Global strategy for the diagnosis, management, and prevention of chronic obstructive pulmonary disease. Updated January 2015. Available at http://www.goldcopd.org/guidelines-global- strategy-for-diagnosis-management.html. Accessed February 19, 2015.

19. Broeders ME, Molema J, Vermue NA, and Folgering HT: Peak inspiratory flow rate and slope of the inhalation profiles in dry powder inhalers. Eur Respir J. 2001;18:780-783.

20. Janssens JP, Pache JC, and Nicold LP: Physiological changes in respiratory function associated with ageing. Eur Respir J. 1999;13:197-205.

21. Janssens W, Vanden Brande P, Hardeman E, de Langhe E, Philps T, Troosters T, and Decramer M: Inspiratory flow rates at different levels of resistance in elderly COPD patients. Eur Respir J. 2008;3:78-83.

22. Dransfield MT, Bourbeau J, Jones PW, Hanania NA, Mahler DA, Vestbo J, Wachtel A, Martinez FJ, Barnhart F, Sanford L, Lettis S, Crim C, and Calverley PM: A once-daily inhaled corticosteroid, long-acting beta2-agonist combination, fluticasone furoate (FF) / vilanterol (VI), for the prevention of COPD exacerbations. Lancet Respir Med. 2013;1:210-223.

23. Martinez FJ, Boscia J, Feldman G, Scott-Wilson C, Kilbride S, Fabbri L, Crim C, and Calverley PM: Fluticasone furoate/ vilanterol $(100 / 25 ; 200 / 25 \mu \mathrm{g})$ improves lung function in COPD: A randomised trial. Respir Med. 2013;107:550-559.

24. Donohue JF, Maleki-Yazdi MR, Kilbride S, Mehta R, Kalberg C, and Church A: Efficacy and safety of once-daily umeclidinium/vilanterol $62.5 / 25 \mathrm{mcg}$ in COPD. Respir Med. 2013;107:1538-1546.

25. Celli B, Crater G, Kilbride S, Mehta R, Tabberer M, Kalberg CJ, and Church A: Once-daily umeclidinium/vilanterol 125/ $25 \mathrm{mcg}$ in COPD: A randomized, controlled study. Chest. 2014;145:981-991.

26. Decramer M, Anzueto A, Kerwin E, Kaelin T, Richard N, Crater G, Tabberer M, Harris S, and Church A: Efficacy and safety of umeclidinium plus vilanterol versus tiotropium, vilanterol, or umeclidinium monotherapies over 24 weeks in patients with chronic obstructive pulmonary disease: Results from two multicentre, blinded, randomised controlled trials. Lancet Respir Med. 2014;2:472-486.

27. Broeders MEAC, Molema J, Hop WCJ, and Folgering HTM: Inhalation profiles in asthmatics and COPD patients: Reproducibility and effect of instruction. J Aerosol Med. 2003;16:131-141.

28. Magnussen H, Watz H, Zimmermann I, Macht S, Greguletz R, Falques M, Jarreta D, and Garcia Gil E: Peak inspiratory flow through the Genuair inhaler in patients with moderate or severe COPD. Respir Med. 2009;103:1832-1837.

Received on April 2, 2015 in final form, August 6, 2015

Reviewed by: Thomas O'Riordan

Tunde Otulana

Address correspondence to: David Prime, PhD GSK Research and Development Ltd Park Road Ware Herts SG12 ODP United Kingdom E-mail: dave.x.prime@gsk.com 